\title{
The Effects of Vitamin D Supplementation in Patients with Knee Osteoarthritis: Uncontrolled Open Label Clinical Trial
}

\author{
Khaled M Alsubiaee ${ }^{1 *}$, Khalid T Alkhathlan ${ }^{1,2},{\text { Amir } \text { Omair }^{1} \text { and Farhan M Alenezi }}^{1}$ \\ ${ }^{1}$ King Abdullah International Medical Research Centre/King Saud bin Abdulaziz University for Health Sciences, Riyadh, Saudi Arabia \\ ${ }^{2}$ King Abdulaziz Medical City, Riyadh, Saudi Arabia
}

"Corresponding author: Khaled M Alsubiaee, College of Medicine, King Saud bin Abdulaziz University for Health Sciences, P.O. Box 5193 Riyadh 1142, Saudi Arabia, Tel: +966558606615; E-mail: Khaledmhd1@hotmail.com

Received date: October 11, 2016; Accepted date: October 31, 2016; Published date: November 07, 2016

Copyright: @ 2016 Alsubiaee KM, et al. This is an open-access article distributed under the terms of the Creative Commons Attribution License, which permits unrestricted use, distribution, and reproduction in any medium, provided the original author and source are credited.

\begin{abstract}
Background: Osteoarthritis $(\mathrm{OA})$ is a degenerative disease that affects joints. The current relationship between low vitamin D levels, functions, and symptoms of osteoarthritis is controversial.

Objective: The aim of this study is to investigate the relationship between knee osteoarthritis and serum levels of vitamin D.

Method: An uncontrolled open label clinical trial conducted on patients with low vitamin D levels using the Western Ontario and McMaster Universities Arthritis Index (WOMAC criteria). The WOMAC criteria used objectively to assess knee-joint function and symptoms before and after vitamin D3 supplementation. The study conducted from March 2013 to October 2015 at King Abdulaziz Medical City. Riyadh, Saudi Arabia. All participants with knee osteoarthritis and low vitamin D levels ( $\leq 75 \mathrm{nmol} / \mathrm{L}$ ) were given $45,000 \mathrm{IU}$ of vitamin D3 orally, once per week for three months, followed by 45,000 IU of vitamin D3 once every two weeks.
\end{abstract}

Results: Of the 100 participants recruited to the study, 58 patients completed the clinical trial and included in the analysis. Nineteen participants excluded due to severe knee OA, vitamin D use, or history of knee surgery, while 23 patients were lost during the follow-up period. Among the 58 patients completing the trial, 39 were females and 19 were males, with an average age of $45.7 \pm 4.5$ years. The WOMAC scores did not change significantly $(P=0.920)$ post-treatment with vitamin $D 3$, despite the significant improvement of vitamin $D$ levels $(P=0.001)$.

Conclusion: This study did not find a relationship between vitamin D levels, knee symptoms and functions in patients with $\mathrm{OA}$.

Keywords: Cholecalciferol; Clinical trial; Knee osteoarthritis; Saudi Arabia

\section{Introduction}

Osteoarthritis (OA) is a degenerative joint disease that usually affects the knees, hips, sacroiliac joint and some distal sacral joints. The knee is the most commonly affected joint in OA with radiological joint space loss, marginal osteophytes, and osseous eburnation, which is a biological degenerative process of the bone [1]. Knee OA is a common age-related disease with one study showing that almost $50 \%$ of adults had symptomatic disease by the age of 85 years [2]. Similarly, a study from Central Saudi Arabia has shown a high age-dependent prevalence of OA, with approximately $60 \%$ of subjects aged $66-75$ years showing evidence of OA [3]. OA clinically diagnosed by radiological studies, in which a decrease in cartilage space appears in standing in the joint space less than three millimeters [1].

There have been several experimental and clinical studies showing a relationship between vitamin D and OA. It was found that vitamin D stimulates the synthesis of proteoglycans by mature chondrocytes. Vitamin D receptors (VDR) found at matrix metalloproteinases
(MMPs) in cartilage with OA in a vitro study using the immunohistochemistry technique [4].

In an epidemiological cohort study, osteophytes on radiological image found in patients with low vitamin D intake and serum levels [5]. Vitamin D deficiency was also shown to have a positive correlation with pain rather than radiological signs in patients with knee OA [6]. Similarly, knee OA patients with vitamin D deficiency found to have more than a two-fold increased risk the disease progression [7]. Vitamin D deficiency appears to be common in the Saudi population, and a high prevalence of vitamin D deficiency in healthy Saudis was observed [8]. In a health survey of 40 primary health care centers, in Jeddah, vitamin D deficiency was found in almost $90 \%$ of healthy Saudis [9]. The high prevalence of vitamin D deficiency that was documented might be an important risk factor for OA in the Saudi population. We hypothesize that vitamin $\mathrm{D}$ supplementation might help alleviate the signs and symptoms of OA in Saudi patients. The aim of this study is to investigate the effects of vitamin D levels using the Western Ontario and McMaster Universities Arthritis Index (WOMAC). 
Page 2 of 3

\section{Methods}

A prospective uncontrolled open label clinical trial was conducted on patients with knee OA from March 2013 to October 2015 at King Abdulaziz Medical City, Riyadh, Saudi Arabia. A written informed consent obtained from all patients prior to the study and required information about $\mathrm{OA}$, vitamin $\mathrm{D}$, and toxicity related to a vitamin $\mathrm{D}$ mega dose provided to all participants. One hundred patients that first came to hospital with OA were randomly chosen for further primary and secondary classification.

Patients with primary knee OA accompanied with low serum vitamin $\mathrm{D}$ levels $(\leq 75 \mathrm{nmol} / \mathrm{L})$ and with no vitamin $\mathrm{D}$ supplementation, regardless of other drugs used, were included. Primary OA was diagnosed by rheumatologists based on clinical and radiological findings. Patients with severe knee OA, and/or kidney disease, and/or a history of knee surgery, and/or those on vitamin D supplementation prior to enrollment were excluded.

Patients who met the study criteria started on vitamin D3 supplementation for a period of six months. For the first three months, an oral dose of 45,000 IU once per week was given, followed by 45,000 IU once every two weeks for another three months. Knee joint assessments were carried out using the WOMAC scoring system at baseline (prior to treatment initiation) and after six months, depending on the patients' willingness to continue the trial and their compliance with the treatment plan. A post-treatment serum vitamin D level was performed at the time of the second knee-joint assessment. The WOMAC scoring system is the most popular objective assessment instrument used to determine the functions and symptoms associated with OA [10].

The WOMAC score instrument used measure pain, stiffness and function of the knee using the Likert scale of five items. The WOMAC instrument was translated into the Arabic language by researchers, and validated, and approved by the research institutional committee, King Abdullah International Medical Research Center (KAIMRC). Interviewing of patients (pre-test), and calling patients by phone (posttest) using the WOMAC instrument was carried out by one researcher to eliminate the bias of interpretation of patients' words and in order to maintain consistency.

The required sample size was determined based on an estimated baseline score of $65 \pm 30$ [11]. It was expected that there would be a minimum of $15 \%$ favorable improvement in the WOMAC score (i.e. a decrease of 10 in the WOMAC score) after intervention with vitamin D supplementation. Based on a $95 \%$ confidence level and $80 \%$ power estimations, the sample size required was determined to be 73 patients. A total of 100 patients were required in the study to account for an estimated loss to follow-up of $20-30 \%$ of the selected sample. The ethical approval was obtained from the Institutional Review Board (IRB), KAIMRC (reference no. IRBC/038/13).

\section{Statistical analysis}

The data analysis was performed using the Statistical Package for the Social Sciences (SPSS) software (Version 20.0. Armonk, NY: IBM Corp.). The descriptive statistics were presented as frequencies and percentages for the categorical variables and as mean \pm standard deviation for the numerical variables. The mean WOMAC scores and vitamin D levels before and after treatment was compared using Paired t-test. A P-value of $<0.05$ is considered as statistically significant for all statistical tests used.

\section{Result}

Eighty-one patients diagnosed with primary OA enrolled into the study. Twenty-three participants (28\%) were lost to follow-up, resulting in 58 participants completing the study and from whom data were available for analysis. The reason for follow-up loss was either inability to contact them, non-compliance with vitamin $\mathrm{D}$ supplementation, and/or they were no longer interested in continuing the study. The demographic characteristics of those patients summarized in Table 1. The mean age of participants was $45.7 \pm 4.5$ years; the majority $(67 \%)$ of patients was females. Bilateral knee-joint OA was found in most of our study population (84\%).

\begin{tabular}{|l|l|}
\hline Variables & Patients \\
\hline Age, mean (SD) & $45.7( \pm 4.5)$ \\
\hline Sex (\%) & \\
\hline Male & $19(33)$ \\
\hline Female & $39(67)$ \\
\hline Joint affected (\%) & \multicolumn{2}{|l|}{} \\
\hline Right & $5(9)$ \\
\hline Left & $4(7)$ \\
\hline Both & $49(84)$ \\
\hline Total & 58 \\
\hline
\end{tabular}

Table 1: Demographic characteristics.

The mean of vitamin $\mathrm{D}$ level significantly increased after the sixmonth treatment with vitamin $\mathrm{D} 3(\mathrm{P}=0.001)$ as shown in Table 2. However, concomitant WOMAC scores did not show a statistically significant increase after vitamin $\mathrm{D} 3$ supplementation $(\mathrm{P}=0.92)$.

\begin{tabular}{|l|l|l|l|}
\hline Variable & Pre-treatment & Post-treatment & $\begin{array}{l}\text { P- } \\
\text { value }\end{array}$ \\
\hline $\begin{array}{l}\text { Vitamin D level, mean in mg/dl } \\
( \pm S D)\end{array}$ & $46.2( \pm 15)$ & $57.2( \pm 21.0)$ & 0.001 \\
\hline WOMAC score $( \pm S D)$ & $45.2( \pm 22.2)$ & $45.3( \pm 21.2)$ & 0.92 \\
\hline WOMAC, & &
\end{tabular}

WOMAC, Western Ontario and McMaster University Arthritis Index

Table 2: Serum vitamin D levels and WOMAC score.

\section{Discussion}

Our study showed no improvement in the WOMAC scores, despite the statistically significant improvement in serum vitamin $D$ levels. Our result is consistent with other published figures [12-14]. A crosssectional study conducted in Kuwait suggested that the level of vitamin $\mathrm{D}$ has no direct correlation with OA severity, neither on x-ray nor by functional assessment [12]. Similarly, another study from Finland showed no relationship between vitamin D levels and OA severity [13]. Moreover, the Boston Medical Center conducted a randomized double-blind trial over two years, involving 146 participants with OA receiving appropriate dosage of vitamin $\mathrm{D}$, which showed no relationship between serum vitamin D level, osteoarthritis pain and cartilage size [14]. However, other studies have shown a correlation 
between vitamin $\mathrm{D}$ level and $\mathrm{OA}$ pain. A controlled clinical trial showed a significant association between serum vitamin $\mathrm{D}$ deficiency and knee OA in patients less than 60 years old [15]. Likewise, Dutch researchers found more disease progression and radiological features seen with a lower vitamin $\mathrm{D}$ diet, particularly in patients with low bone mineral density. They suggest that improving vitamin $\mathrm{D}$ levels in elderly patients, especially those with lower bone mineral density, may protect against onset osteoarthritis progression [16]. Recently, vitamin $\mathrm{D}$ deficiency was pointed out as a risk factor for pain in OA in black Americans [17]. In a case-control study, post-menopausal Egyptian women with $\mathrm{OA}$ found to have significantly lower vitamin D levels compared to those without OA [18]. Furthermore, a study conducted in Iran showed significant improvement in WOMAC scores and visual analogue scale (VAS), as well as quadriceps muscle strength, in patients with knee OA after serum vitamin D level correction [19].

The current study has several limitations, such as its low sample size, lack of a control group, lack of radiological assessment, and no VAS used. Moreover, the small sample size might have contributed to not being able to detect a real difference in the WOMAC scores. Other limitations could be that the time of study is considerably short, given the chronic nature of $\mathrm{OA}$; a treatment profile should be examined over a longer period.

\section{Conclusion}

It is unlikely that vitamin $\mathrm{D}$ has a role in alleviating the pain of knee OA or its functionality. Further studies, with larger sample sizes and more assessment tools, are needed to adequately address the relationship between vitamin $\mathrm{D}$ level and knee OA.

\section{Ethics Approval and Consent to Participate}

Written informed consent was obtained from patients and approval was obtained from King Abdullah International Medical Research Center

\section{Authors' Contribution}

Khaled M Alsubiaee initiated the study proposal, contributed to the collection and interpretation of the data, analysed and drafted the manuscript. Khalid T Alkhathlan, Amir Omair, Farhan M Alenezi contributed to the collection and interpretation of the data and revised the manuscript. All authors approved the final version of the manuscript.

\section{Disclosure of Conflict of Interest}

All authors have no conflict of interest to report.

\section{Acknowledgements}

We would like to Acknowledge and thank Dr. Mohammed Al-Jasser, Assistant Professor of Dermatology at King Saud bin Abdulaziz University for Health Sciences for his comprehensive review for this study.

\section{Funding}

The study had been conducted by researchers with official funding by King Abdullah International Medical Research Center (KAIMRC).

\section{References}

1. Murphy L, Schwartz TA, Helmick CG, Renner JB, Tudor G, et al. (2008) Lifetime risk of symptomatic knee osteoarthritis. Arthritis Rheum 59: 1207-1213.

2. Al-Arfaj AS, Alballa SR, Al-Saleh SS, Al-Dalaan AM, Bahabry SA, et al. (2003) Knee osteoarthritis in Al-Qaseem, Saudi Arabia. Saudi Med J 24: 291-293.

3. Hochberg MC, Silman AJ, Smolen JS, Weinblatt ME, Weisman MH (2015) Rheumatology. (6th edtn). Elsevier Mosby, Philadelphia, Pennsylvania, USA.

4. Tetlow LC, Woolley DE (2001) Expression of vitamin D receptors and matrix metalloproteinases in osteoarthritic cartilage and human articular chondrocytes in vitro. Osteoarthritis and Cartilage 9: 423-431.

5. Arden NK, Richardson A, Syddall HE, Sayer AA, Dennison EM, et al (2006) A32 Dietary vitamin D intake and radiographic knee osteoarthritis. Osteoarthritis and Cartilage 14: S33-S34.

6. Muraki S, Dennison E, Jameson K, Boucher BJ, Akune T, et al. (2011) Association of vitamin D status with knee pain and radiographic knee osteoarthritis. Osteoarthritis and Cartilage 19: 1301-1306.

7. Zhang FF, Driban JB, Lo GH, Price LL, Booth S, et al. (2004) Vitamin D Deficiency is Associated with Progression of Knee Osteoarthritis. J Nutr 144: 2002-2008.

8. Elsammak MY, Al-Wossaibi AA, Al-Howeish A, Alsaeed J (2011) High prevalence of vitamin D deficiency in the sunny Eastern region of Saudi Arabia: a hospital-based study. East Mediterr Health J 17: 317-322.

9. Ardawi MSM, Sibiany AM, Bakhsh TM, Qari MH, Maimani AA (2012) High prevalence of vitamin D deficiency among healthy Saudi Arabian men: relationship to bone mineral density, parathyroid hormone, bone turnover markers, and lifestyle factors. Osteoporos Int 23: 675-686.

10. Bellamy N, Buchanan WW, Goldsmith CH, Campbell J, Stitt LW (1988) Validation study of WOMAC: A health status instrument for measuring clinically important patient relevant outcomes to anti-rheumatic drug therapy in patients with osteoarthritis of the hip or knee. J Rheumatol 15: 1833-1840.

11. Hmamouchi I, Allali F, Tahiri L, Khazzani H, Mansouri LE, et al. (2012) Clinically important improvement in the WOMAC and predictor factors for response to non-specific non-steroidal anti-inflammatory drugs in osteoarthritic patients: a prospective study. BMC Res Notes 5: 58.

12. Al-Jarallah KF, Shehab D, Al-Awadhi A, Nahar I, Haider MZ, et al. (2012) Are $25(\mathrm{OH}) \mathrm{D}$ levels related to the severity of knee osteoarthritis and function? Med Princ Pract 21: 74-78.

13. Konstari S, Paananen M, Heliövaara M, Knekt P, Marniemi J, et al. (2012) Association of 25-hydroxyvitamin D with the incidence of knee and hip osteoarthritis: a 22-year follow-up study. Scand J Rheumatol 41: 124-131.

14. McAlindon T, Lavalley M, Schneider E, Nuite M, Lee JY, et al. (2013) Effect of vitamin D supplementation on progression of knee pain and cartilage volume loss in patients with symptomatic osteoarthritis: a randomized controlled trial. JAMA 309: 155-162.

15. Heidari B, Heidari P, Hajian-Tilaki K (2011) Association between serum vitamin D deficiency and knee osteoarthritis. Int Orthop 35: 1627-1631.

16. Bergink AP, Uitterlinden AG, Van Leeuwen JP, Buurman CJ, Hofman A, et al. (2009) Vitamin D status, bone mineral density, and the development of radiographic osteoarthritis of the knee: The Rotterdam Study. J Clin Rheumatol 15: 230-237.

17. Glover TL, Goodin BR, Horgas AL, Kindler LL, King CD, et al. (2012) Vitamin D, race, and experimental pain sensitivity in older adults with knee osteoarthritis. Arthritis Rheum 64: 3926-3935.

18. Abu el Maaty MA, Hanafi RS, El Badawy S, Gad MZ (2013) Association of suboptimal 25-hydroxyvitamin D levels with knee osteoarthritis incidence in post-menopausal Egyptian women. Rheumatol Int 33: 2903-2907.

19. Heidari B, Javadian Y, Babaei M, Ghahari BY (2015) Restorative Effect of Vitamin D Deficiency on Knee Pain and Quadriceps Muscle Strength in Knee Osteoarthritis. Acta Medica Iranica 53: 466-470. 